\title{
An Efficient Route to Highly Substituted Indoles via Tetrahydroindol-4(5H)-one Intermediates Produced by Ring- Opening Cyclization of Spirocyclopropanes with Amines
}

\author{
Hisanori Nambu, ${ }^{*}$ Wataru Hirota, Masahiro Fukumoto, Takafumi Tamura, and Takayuki Yakura*[a]
}

\begin{abstract}
An efficient route to highly substituted indoles was developed. It includes regioselective functionalization of tetrahydroindol-4(5H)-ones, prepared by ring-opening cyclization of cyclohexane-1,3-dione-2-spirocyclopropanes with primary amines, and subsequent oxidation. 6-Substituted indoles were synthesized from a readily available 5-substituted cyclohexane-1,3-dione-2spirocyclopropane. Synthesis of 5- and 7-substituted indoles was achieved by regioselective electrophilic alkylation of tetrahydroindol$4(5 H)$-one, followed by oxidation. 4-Substituted indoles were synthesized by nucleophilic alkylation of the corresponding pyrrole derivative, prepared by partial oxidation of tetrahydroindol-4(5H)-one, and a sequential oxidation. Synthesis of 4-substituted indoles was also accomplished by Pd-catalyzed coupling of 4-hydroxyindolederived triflates. Furthermore, synthesis of 4,5,6,7-tetrasubstituted indoles was achieved by using these regioselective alkylations.
\end{abstract}

\section{Introduction}

Indoles are important structural components of a wide range of biologically-active alkaloids and pharmaceutical agents. ${ }^{[1]}$ Consequently, the development of efficient synthetic methods for indoles continues to attract considerable attention. ${ }^{[2]}$ Although a number of effective approaches to indoles substituted on the nitrogen-containing pyrrole ring have been reported, there are only a few examples of regiocontrolled access to indoles bearing multiple substituents on the benzene ring ${ }^{[3]}$ because of the lower reactivity of the benzene moiety. In general, there are three approaches to indoles possessing substituents on the benzene ring; (A) pyrrole ring formation from substituted aniline derivatives, $(B)$ benzene ring formation from pyrroles possessing side chains, and $(C)$ regioselective functionalization of nonsubstituted indoles (Scheme 1). Representative examples of approach A include the Larock and Kerr indole syntheses. Larock group reported Pd-catalyzed coupling between highly substituted o-iodoanilines and alkynes to afford highly substituted indole derivatives (Scheme 1, eq. 1). ${ }^{[4]}$ Kerr and coworkers developed a Diels-Alder/Plieninger indolization sequence ${ }^{[5,6]}$ and demonstrated its application to total syntheses of natural products (Scheme 1, eq. 2) ${ }^{[7]}$ As representative examples of approach B, two synthetic methods are illustrated. Natsume et al. reported the synthesis of indoles that were alkyl- and alkoxy-substituted in the benzene portion employing acidcatalyzed cyclization of pyrroles possessing side chains, ${ }^{[8]}$ and demonstrated the utility of this approach through the syntheses of various natural products (Scheme 1, eq. 3). ${ }^{[9]}$ Yanagisawa and Yoshida developed the synthetic method for highly substituted indoles employing the ring-closing olefin metathesis (RCM)/dehydration sequence of highly functionalized pyrrole precursors (Scheme 1, eq. 4). ${ }^{[10]}$ Recently, approach C, i.e., the direct introduction of substituents onto the indole benzene ring by transition-metal-catalyzed $\mathrm{C}-\mathrm{H}$ functionalization was reported (Scheme 1, eq. 5). ${ }^{[11-15]}$ Regioselective functionalization at the C4 $\left(R^{4}\right)^{[12,13]}$ and C7 $\left(R^{3}\right)^{[14]}$ positions was achieved by employing directing groups at $\mathrm{C} 3\left(\mathrm{R}^{2}\right)$ and $\mathrm{N} 1\left(\mathrm{R}^{1}\right)$, respectively. Although these synthetic approaches to highly substituted indoles are useful for the synthesis of specific indoles, they still involve some drawbacks, such as difficulties in the preparation of the cyclization precursors and the limitation of introducible positions. Therefore, the development of efficient and flexible methods for the synthesis of highly substituted indoles remains challenging and highly desirable.

\footnotetext{
[a] Dr. H. Nambu, W. Hirota, M. Fukumoto, T. Tamura, Prof. Dr. T. Yakura

Graduate School of Medicine and Pharmaceutical Sciences University of Toyama

Sugitani, Toyama 930-0194 (Japan)

Fax: (+81)76-434-5053

E-mail: nambu@pha.u-toyama.ac.jp; yakura@pha.u-toyama.ac.jp
}

Supporting information for this article is given via a link at the end of the document.((Please delete this text if not appropriate)) 
A. Approach from highly substituted aniline derivatives 'Larock indole synthesis:

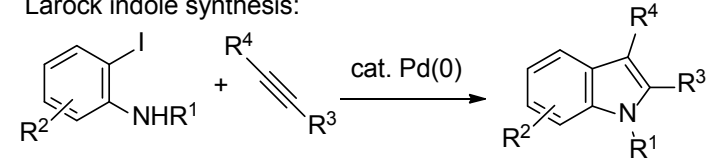

'Kerr indole synthesis:<smiles>[R]/C=C(/[R])C([R])C[R]</smiles>

B. Approach from pyrroles possessing side chains

Natsume indole synthesis:

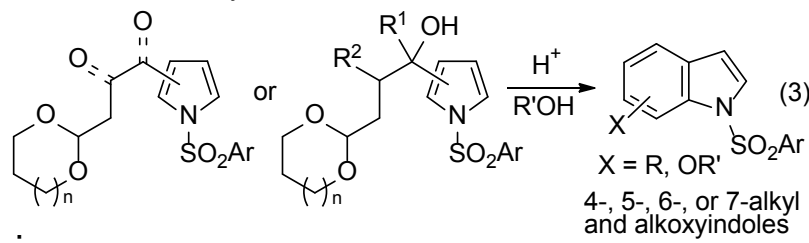

'Yanagisawa and Yoshida indole synthesis:

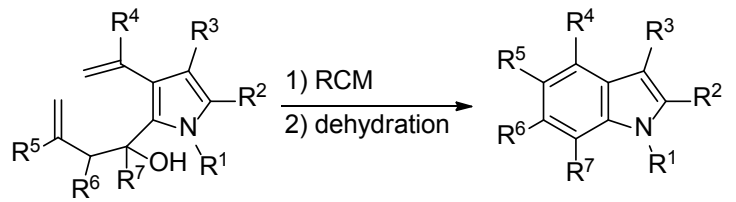

C. Approach by regioselective $\mathrm{C}-\mathrm{H}$ functionalizations of indoles

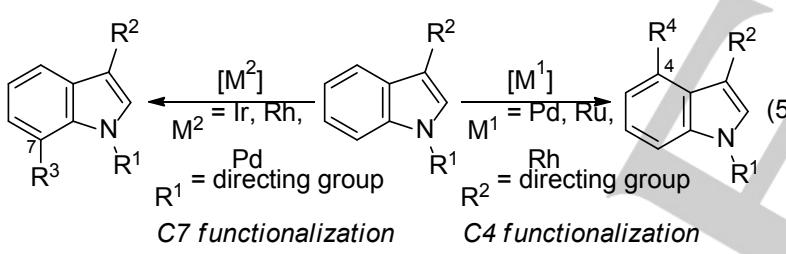

Scheme 1. Synthetic approaches to highly substituted indoles.

As a part of our efforts toward the synthesis of functionalized indoles based on cyclopropane chemistry, ${ }^{[16]}$ we recently reported a novel synthesis of 4-hydroxyindole $\mathbf{4 a}$ through 2,3,6,7-tetrahydro- $1 \mathrm{H}$-indol-4(5H)-one $\mathbf{2 a}$. The ring-opening cyclization of cyclohexane-1,3-dione-2-spirocyclopropane 1a with benzylamine and the subsequent stepwise oxidation of the resulting product $2 \mathrm{a}$ gave 4-hydroxyindole $4 a$ via 4 hydroxyindoline $3 \mathbf{a}$ in high overall yield (Scheme 2) ${ }^{[17]}$ Herein, we report an efficient route to highly substituted indoles employing regioselective alkylations of $\mathbf{2}$ as a key synthetic intermediate.

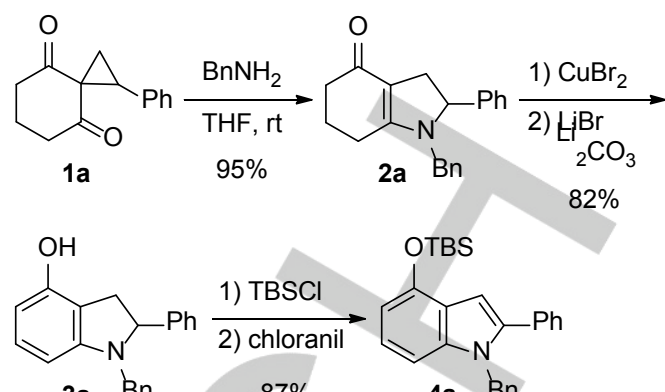

Scheme 2. Synthesis of 4-hydroxyindole $4 a$ via the ring-opening cyclization of cyclohexane-1,3-dione-2-spirocyclopropane 1a with benzylamine.

\section{Results and Discussion}

Synthetic strategy for highly substituted indoles

Our synthetic strategy for indoles bearing multiple substituents on the benzene ring is outlined in Scheme 3 . Because $\mathbf{2 a}$ is easily oxidized to 4-hydroxyindole $\mathbf{4 a}$, we planned to use functionalized tetrahydroindol-4(5H)-ones as potential key synthetic intermediates for substituted indoles. 6-Substituted tetrahydroindol-4 $(5 H)$-one $2\left(R^{1} \neq \mathrm{H}\right)$ can be prepared from 5 substituted cyclohexane-1,3-dione-2-spirocyclopropane $1\left(R^{1}\right.$ $\neq \mathrm{H}$ ) according to our ring-opening cyclization procedure. ${ }^{[17]}$ Tetrahydroindol-4(5H)-one 2 substituted at the other positions could be regioselectively converted from non-substituted 2 using its several reactive sites based on its $\beta$-enaminone structure: 2 can react with an electrophile as the corresponding enolate at the $\alpha^{\prime}$ - and $\gamma$-positions of the enaminone (i.e., the 5- and 7positions of the indole), and can also react with a nucleophile at the carbonyl carbon (4-position). After regioselective functionalization of $\mathbf{2}$, the resulting products $\mathbf{5}, \mathbf{7}$, and $\mathbf{9}$ would be readily oxidized to the 5-, 7-, and 4-substituted indoles 6,8 , and 10, respectively. Alternatively, transition-metal-catalyzed coupling of indole-4-O-triflate 11 would produce the 4substituted indole $\mathbf{1 0}$ and also the non-substituted 12. 


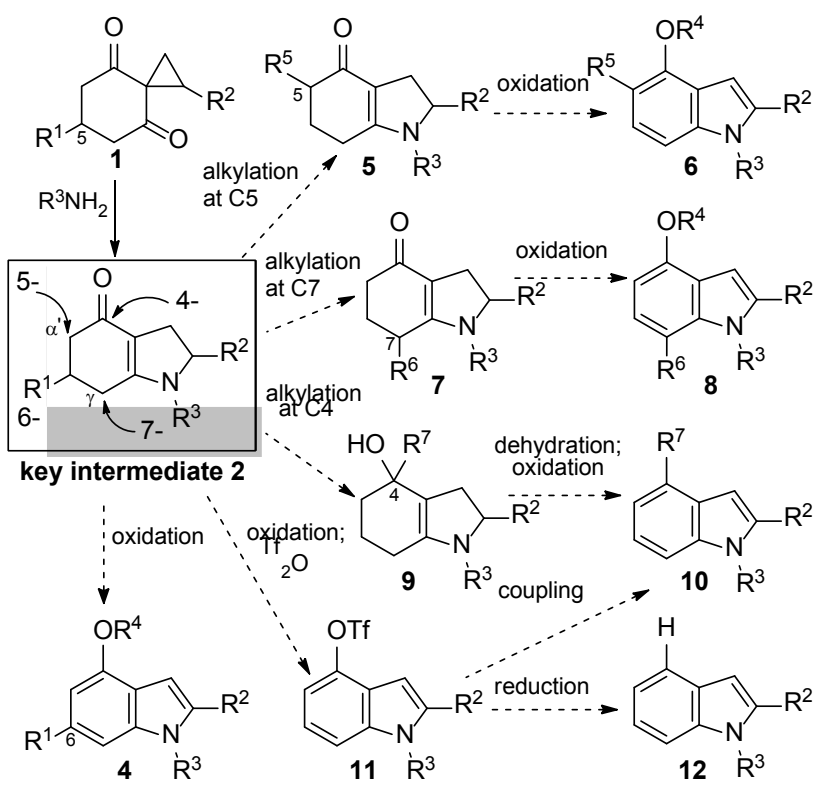

Scheme 3. Strategy for syntheses of highly substituted indoles.

\section{Synthesis of 6-substituted indole derivatives}

We initially synthesized 6-substituted indoles according to our published method, as shown in Scheme 2. When 5methylcyclohexane-1,3-dione-2-spirocyclopropane $\mathbf{1 b}^{[18]}$ was reacted with benzylamine in tetrahydrofuran (THF) at room temperature, the ring-opening cyclization reaction proceeded smoothly to provide 6-methyltetrahydroindol-4(5H)-one $\mathbf{2 b}$ in $98 \%$ yield (Scheme 4 ). Oxidation of $\mathbf{2 b}$ to indoline $\mathbf{3 b}$ was achieved by bromination with $\mathrm{CuBr}_{2}$ followed by aromatization using a combination of $\mathrm{LiBr}$ and $\mathrm{Li}_{2} \mathrm{CO}_{3}$. After protection of the phenolic hydroxy group in $\mathbf{3 b}$ as a tert-butyldimethylsilyl (TBS) ether, oxidation of $\mathbf{1 3}$ with chloranil furnished 6-methylindole $\mathbf{4 b}$ in $75 \%$ yield from $\mathbf{3 b}$. Furthermore, we explored a sequential conversion of these processes. Ring-opening cyclization of $\mathbf{1 b}$ followed by oxidation to indole proceeded without purification of any intermediate by column chromatography on silica gel, providing $4 \mathrm{~b}$ in $51 \%$ overall yield.

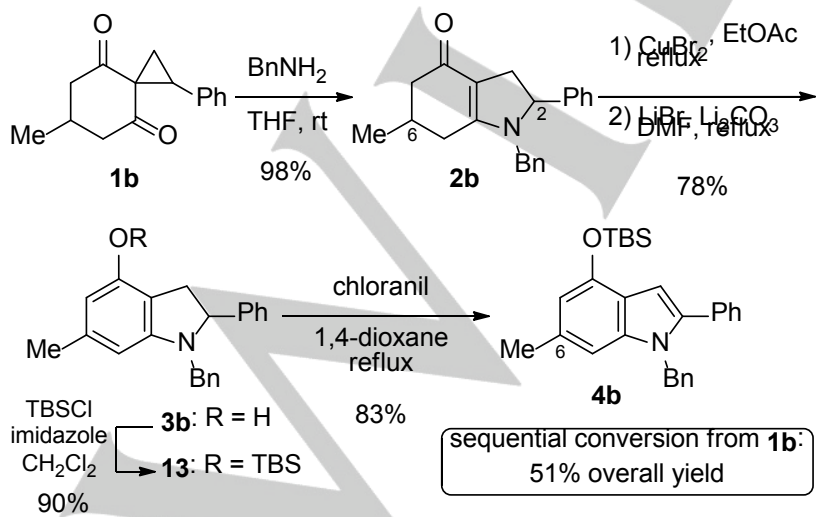

\section{Synthesis of 5- and 7-substituted indole derivatives}

Next, the synthesis of 5- and 7-substituted indole derivatives was investigated. Mariano and co-workers reported regioselective enolization and alkylation of $\beta$-enaminones. ${ }^{[19]}$ The $\alpha$-alkylated product was obtained through kinetic enolate formation when using lithium diisopropylamide (LDA) as a base, whereas the $\gamma$-alkylated product was formed through thermodynamic enolate formation when using lithium hexamethyldisilazide (LiHMDS). Therefore, we applied this protocol to regioselective alkylation of 2 with alkyl halides (Table 1). 2a was reacted with LDA in THF at $-78{ }^{\circ} \mathrm{C}$, and then the reaction was quenched with methyl iodide at $-78{ }^{\circ} \mathrm{C}$ to $\mathrm{rt}$ to afford 5 -methylated product $\mathbf{5 a}$ in $89 \%$ yield (entry 1 ). Similar reactions of $2 a$ with benzyl and allyl bromides as the alkyl halide gave 5 -benzylated and 5 -allylated products $\mathbf{5 b}$ and $\mathbf{5 c}$ in $76 \%$ and $59 \%$ yields, respectively (entries 2 and 3 ). Conversely, the reaction of $\mathbf{2 a}$ with methyl iodide using LiHMDS as a base produced 7 -methylated product $7 \mathrm{a}$ in $84 \%$ yield (entry 4 ). Regioselective benzylation and allylation at $\mathrm{C} 7$ were also achieved by using LiHMDS and 7-benzylated and allylated products $\mathbf{7 b}$ and $7 \mathrm{c}$ were obtained in $89 \%$ and $71 \%$ yields, respectively (entries 5 and 6 ).

Table 1. Regioselective alkylation of $\mathbf{2 a}$ using LDA or LiHMDS. ${ }^{\text {[a] }}$

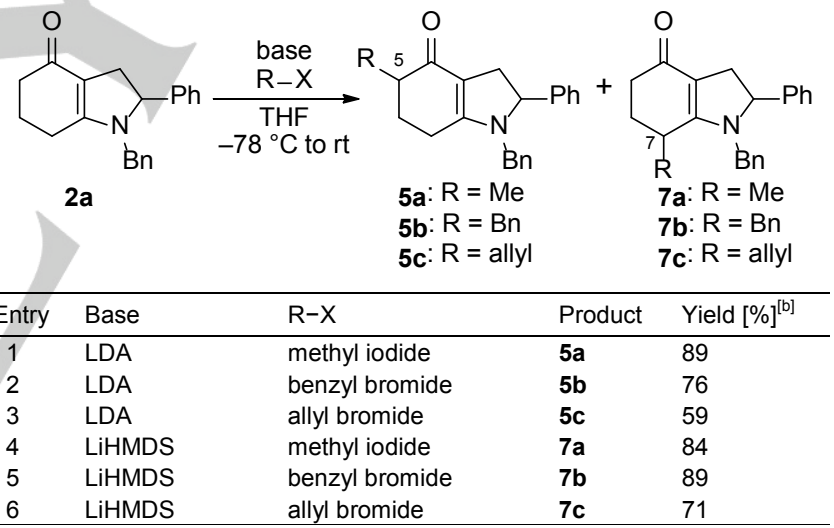

[a] All reaction were performed on a $0.2 \mathrm{mmol}$ scale with 1.5 equiv of alky halides and 1.5 equiv (for LDA) or 1.3 equiv (for LiHMDS) of bases. [b] All products were isolated as a diastereomeric mixture.

Next, we performed the conversion of the 5- and 7-alkylated products into indoles (Scheme 5). According to Schemes 2 and 4 , the bromination of 5- and 7-methyl compounds $5 \mathrm{a}$ and $7 \mathrm{a}$ with $\mathrm{CuBr}_{2}$ followed by aromatization using $\mathrm{LiBr}$ and $\mathrm{Li}_{2} \mathrm{CO}_{3}$ provided the corresponding indoline products 14 and 15 in $86 \%$ and $50 \%$ yields, respectively. After protection of the phenolic hydroxy groups in 14 and 15 with TBSCl to give the corresponding silyl ethers 16 and 17 in $98 \%$ and $86 \%$ yields, treatment of 16 and 17 with chroranil afforded 5-methylindole $\mathbf{6 a}$ and 7-methylindole $\mathbf{8 a}$ in $58 \%$ and $83 \%$ yields, respectively. Oxidation of 16 with $\mathrm{MnO}_{2}$ furnished $6 \mathbf{6}$ in $83 \%$ yield. Thus, regioselective synthesis of 5 and 7-methylindoles was achieved. 


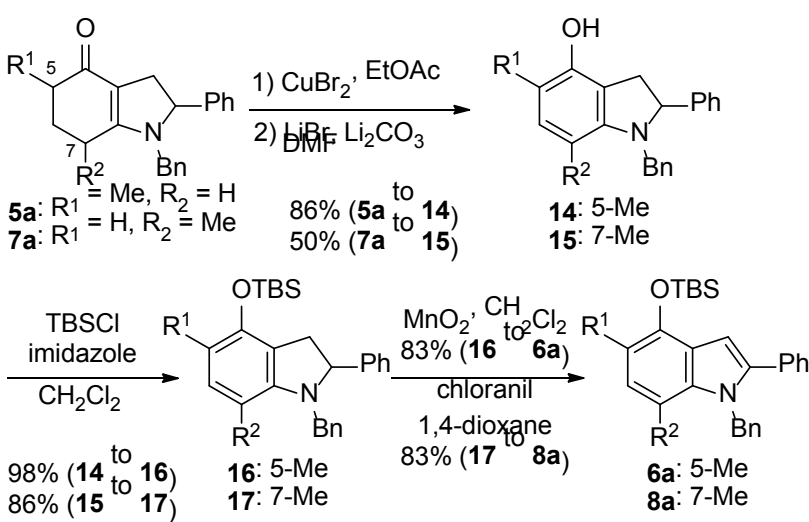

Scheme 5. Synthesis of 5-methyl and 7-methylindole derivatives $\mathbf{6 a}$ and $\mathbf{8 a}$.

\section{Synthesis of 4-substituted indole derivatives}

4-Substituted indole 10 was obtained by nucleophilic addition to the carbonyl group at $\mathrm{C} 4$ of the tetrahydroindol-4(5H)-one. We initially investigated the reaction of $2 \mathbf{a}$ with nucleophiles (Scheme 6). However, the reaction of $\mathbf{2} \mathbf{a}$ with methyllithium gave a complex mixture of products and tertiary alcohol 9a was not detected. We assumed that the electrophilicity of the carbonyl group in $2 \mathrm{a}$ was reduced by the donating effect of the nitrogen atom. Therefore, we planned to oxidize $2 a$ to pyrrole 18 prior to addition of the nucleophile to the carbonyl carbon. The tertiary alcohol 19 obtained by the addition of a nucleophile to ketone could be converted into 4-substituted indole derivative 10 by dehydration and subsequent oxidation.

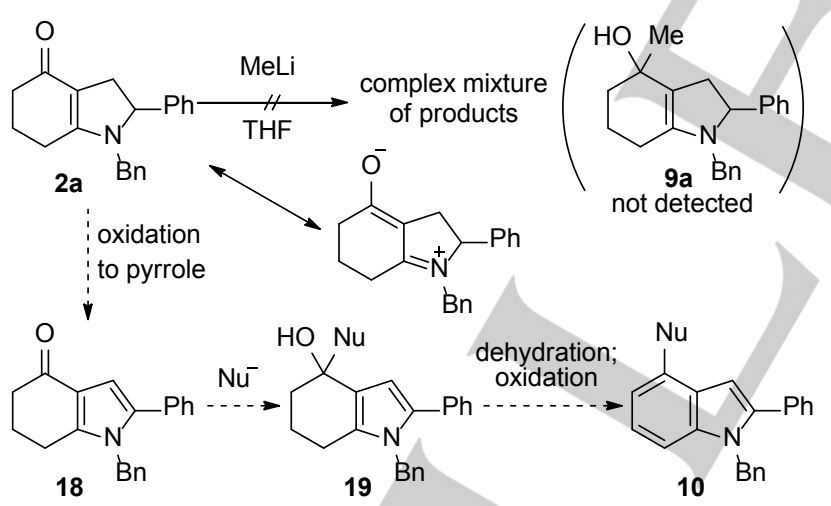

Scheme 6. Attempts to introduce the methyl group at $\mathrm{C} 4$ and a synthetic strategy for 4-substituted indole 10.

Conversion of tetrahydroindol-4(5H)-one $2 \mathrm{a}$ to pyrrole $\mathbf{1 8}$ was somewhat troublesome (Table 2). The usual oxidation with $\mathrm{DDQ}$ and dehydrogenation with $\mathrm{Pd} / \mathrm{C}$ gave only trace amounts of 18 (entries 1 and 2), and the reaction with chloranil in 1,4dioxane afforded 18 in moderate yield (entry 3). Gratifyingly, we found that $\mathrm{MnO}_{2}$ was the most effective oxidant for $2 \mathrm{a}$ and gave 18 in $90 \%$ yield (entry 4 ).
Table 2. Oxidation of $\mathbf{2 a}$ to pyrrole 18

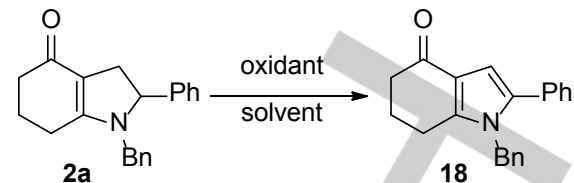

\begin{tabular}{cllcl}
\hline Entry & Oxidant & Solvent & $t[\mathrm{~h}]$ & Yield $(\%)$ \\
\hline 1 & $\mathrm{DDQ}$ & 1,4-dioxane & 3 & trace \\
2 & $\mathrm{Pd} / \mathrm{C}$ & EtOAc & 24 & trace \\
3 & chloranil & $1,4-$ dioxane & 1 & 60 \\
4 & $\mathrm{MnO}_{2}$ & $\mathrm{CH}_{2} \mathrm{Cl}_{2}$ & 1 & 90 \\
\hline
\end{tabular}

We then examined nucleophilic addition to pyrrole 18 (Scheme 7). The reaction of 18 with methyllithium in THF proceeded smoothly to produce a mixture of exo- and endoolefin 20 through methylation of the ketone and subsequent dehydration of the resulting tertiary alcohol. The conjugated olefin $\mathbf{2 0}$ was easily oxidized with chloranil, and 4-methylindole derivative $10 \mathrm{a}$ was obtained in $64 \%$ yield from 18 . The reaction of 18 with phenyllithium also occurred very well to afford conjugated olefin $\mathbf{2 1}$ and a sequential oxidation with chloranil gave 4-phenylindole derivative $10 \mathrm{~b}$ in $84 \%$ yield from 18 . To demonstrate the utility of this synthetic method, we investigated the removal of the benzyl protecting group. According to the procedure of Deaton-Rewolinski, ${ }^{[20]}$ treatment of $\mathrm{N}$-benzylindole $10 \mathrm{a}$ with potassium tert-butoxide/dimethyl sulfoxide (DMSO) and oxygen at room temperature afforded $N$-debenzylated product $10 \mathrm{c}$ in $76 \%$ yield.

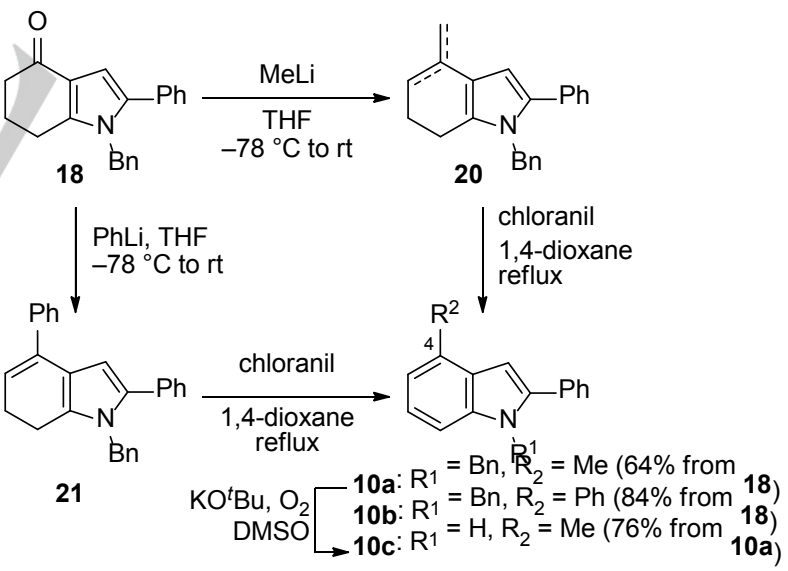

Scheme 7. Synthesis of 4-methyl and 4-phenylindoles 10a-c.

Introduction of C4 substitutions by Pd-catalyzed coupling of triflates

Here, we demonstrate the transition-metal-coupling method for the synthesis of 4-phenylindole $10 \mathrm{~b}$ from 4-hydroxyindole as an alternative (Scheme 8), because it has been disclosed that the 4-hydroxy group of the indole could be converted into other substituents, such as alkynyl, aryl, or hydro groups, by transition-metal-catalyzed coupling of the corresponding $O$ triflate. ${ }^{[3 g, 21]}$ Bromination of pyrrole 18 with $\mathrm{CuBr}_{2}$ followed by 
aromatization using $\mathrm{LiBr}$ and $\mathrm{Li}_{2} \mathrm{CO}_{3}$ provided the corresponding 4-hydroxyindole $\mathbf{2 2}^{[22]}$ in $64 \%$ yield. Reaction of 22 with triflic anhydride and pyridine afforded indole triflate 11a in $86 \%$ yield. Pd-catalyzed coupling of 11a with phenylboronic acid and $\mathrm{Cs}_{2} \mathrm{CO}_{3}$ proceeded smoothly to provide 4-phenylindole $10 \mathrm{~b}$ in $86 \%$ yield. Furthermore, reductive coupling of $11 \mathrm{a}$ and formic acid in the presence of $\mathrm{Pd}(\mathrm{OAc})_{2}$ afforded 4-hydroindole 12a in $73 \%$ yield. These results indicate that a variety of 4-substituted indole derivatives can be synthesized via the Pd-catalyzed coupling of indole triflates.<smiles>Cc1cc2c(n1C)CCCC2=O</smiles>
$\mathrm{Bn}$

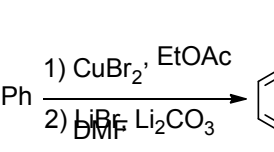

$64 \%$<smiles></smiles><smiles>COCCOCCOCCOCc1cc2c(O)cccc2n1-c1ccccc1</smiles>
22 $\mathrm{Bn}$

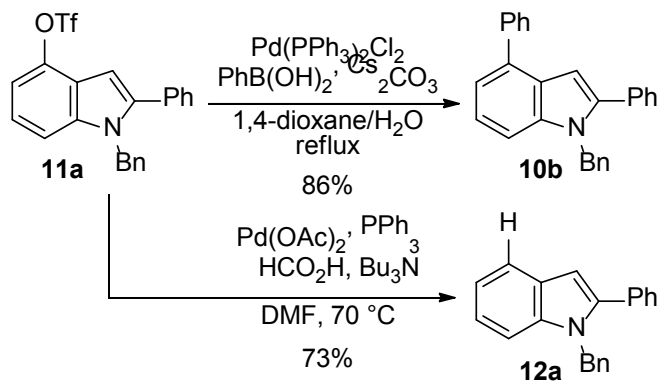
$10 \mathrm{~b} B \mathrm{Bn}$ 11a $\mathrm{Bn}$ $73 \%$

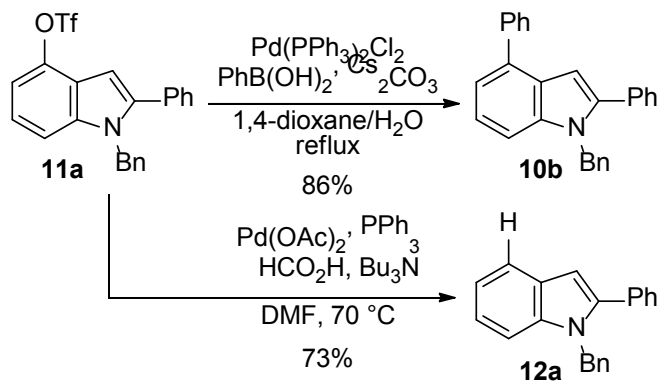

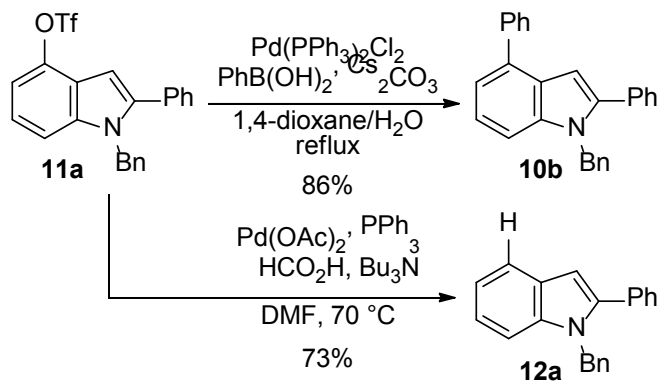

$86 \%$

Scheme 8. Synthesis of 4-phenylindoles $10 \mathrm{~b}$ and 4-hydroindole 12a via indole triflate 11a.

\section{Synthesis of 4,5,6,7-tetrasubstituted indole derivatives}

Having achieved the regioselective alkylation of tetrahydroindol$4(5 \mathrm{H})$-one 2, we then investigated the synthesis of indoles possessing fully substituted benzene rings, such as $4,5,6,7-$ tetramethylindoles 27a and 27b (Scheme 9). C7-Selective methylation of 6 -methyltetrahydroindol-4(5H)-ones $\mathbf{2 b}(\mathrm{R}=\mathrm{Ph})$ and $2 c(R=H)^{[23]}$ using LiHMDS and methyl iodide followed by C5-selective methylation with LDA and methyl iodide afforded 5,6,7-trimethyl derivatives $24 \mathrm{a}$ and $\mathbf{2 4 b}$ in $88 \%$ and $74 \%$ yields, respectively. After oxidation of $\mathbf{2 4 a}$ and $\mathbf{2 4 b}$ with chloranil, C4selective methylation of pyrroles $\mathbf{2 5 a}$ and $\mathbf{2 5 b}$ with methyllithium followed by oxidation of conjugated olefins $\mathbf{2 6 a}$ and $\mathbf{2 6 b}$ with chloranil furnished 4,5,6,7-tetramethylindoles $\mathbf{2 7 a}$ and $\mathbf{2 7 b}$ in $59 \%$ and $79 \%$ yields, respectively.

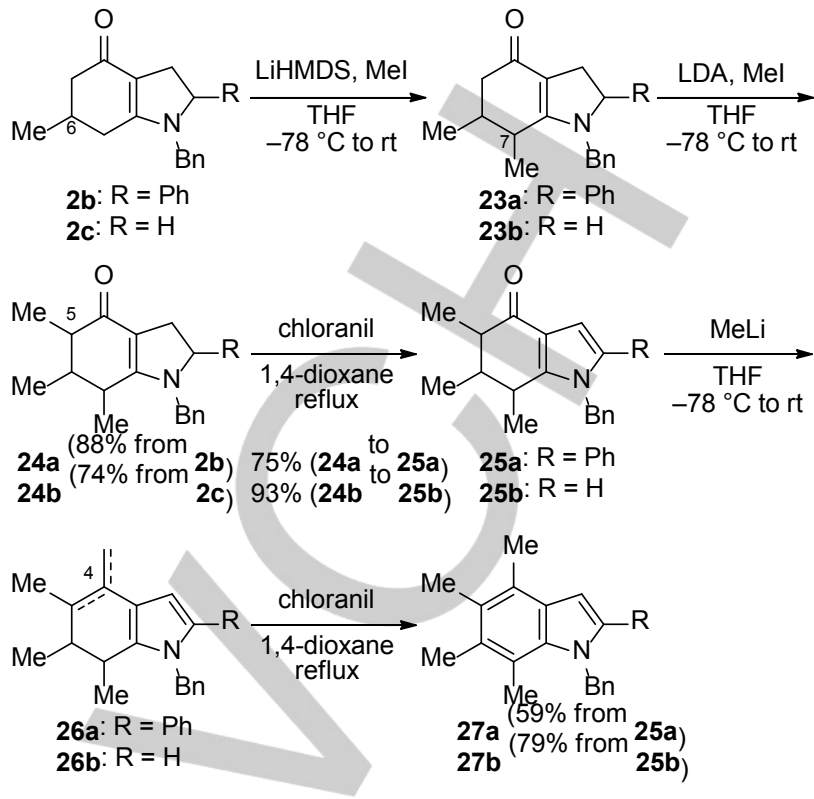

Scheme 9. Synthesis of 4,5,6,7-tetramethyl-substituted indoles $\mathbf{2 7 a}$ and $\mathbf{2 7}$ b.

Finally, the synthesis of indole bearing various substitutions on the benzene ring was examined (Scheme 10). C7-Selective benzylation of 6-methyltetrahydroindol-4(5H)-one 2c with benzyl bromide using LiHMDS and sequential C5-selective allylation with allyl bromide using LDA provided 5-allyl-7-benzyl-6-methylsubstituted product $\mathbf{2 8}$ in $56 \%$ yield. After oxidation to pyrrole $\mathbf{2 9}$ with chloranil (55\% yield), C4-selective phenylation of 29 with phenyllithium followed by oxidation with chloranil furnished 5allyl-1,7-dibenzyl-6-methyl-4-phenylindole (30) in 31\% yield. The regioselectivity of $\mathbf{3 0}$ was confirmed by an observed ${ }^{1} \mathrm{H}$ NOE correlation between N1- and C7-benzylic protons.<smiles>C=CCC1C(=O)C2=C(C(Br)C1C)N(Cc1ccccc1)CC2[18OH]</smiles>

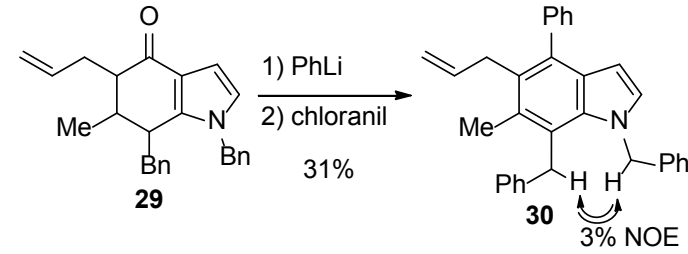

Scheme 10. Synthesis of 4,5,6,7-tetrasubstituted indole $\mathbf{3 0}$

\section{Conclusions}

We demonstrated the syntheses of highly substituted indoles via the common synthetic intermediates tetrahydroindol-4(5H)-ones. 6-Methyl-substituted indoles were synthesized from a readily available 5-methylcyclohexane-1,3-dione-2-spirocyclopropane. 
Synthesis of 5- and 7-methyl-substituted indoles was achieved by regioselective methylation of tetrahydroindol-4(5H)-one followed by oxidation to indoles. 4-Methyl-substituted indoles were synthesized by oxidation to the pyrrole derivative, methylation with methyllithium, and oxidation to the indole. In addition, synthesis of 4,5,6,7-tetrasubstituted indoles was achieved from 6-methyl-substituted tetrahydrondol-4(5H)-ones using these regioselective alkylations. Further application of the present synthetic method to the synthesis of biologically active indole alkaloids is currently in progress.

\section{Experimental Section}

Typical procedure for the regioselective alkylation of tetrahydroindol-4(5H)-ones 2 and 23 with LDA (Table 1, Schemes 9 and 10)

A solution of LDA (1.0 M in THF, $0.30 \mathrm{~mL}, 0.30 \mathrm{mmol}$ ) was added to a solution of tetrahydroindol- $4(5 \mathrm{H})$-one $2 \mathrm{a}(61 \mathrm{mg}, 0.20 \mathrm{mmol})$ in THF (2 $\mathrm{mL}$ ) at $-78^{\circ} \mathrm{C}$. After stirring at $-78{ }^{\circ} \mathrm{C}$ for $1 \mathrm{~h}$, methyl iodide $(0.019 \mathrm{~mL}$, $0.30 \mathrm{mmol}$ ) was added to the mixture and the whole was allowed to warm to room temperature over $1 \mathrm{~h}$. The reaction mixture was quenched with saturated aqueous $\mathrm{NH}_{4} \mathrm{Cl}(5 \mathrm{~mL})$, and the whole mixture was extracted with EtOAc $(2 \times 5 \mathrm{~mL})$. The combined organic layers were washed with water $(5 \mathrm{~mL})$ and brine $(5 \mathrm{~mL})$, and dried over anhydrous $\mathrm{MgSO}_{4}$. Filtration and evaporation in vacuo furnished the crude product, which was purified by column chromatography (silica gel, $4 \% \mathrm{Et}_{3} \mathrm{~N}$ in EtOAc) to provide 5-methylated product $\mathbf{5 a}(57 \mathrm{mg}, 89 \%)$.

Typical procedure for the regioselective alkylation of tetrahydroindol-4(5H)-ones 2 with LiHMDS (Table 1, Schemes 9 and 10)

A solution of LiHMDS ( $0.83 \mathrm{M}$ in THF/hexane, $0.66 \mathrm{~mL}, 0.55 \mathrm{mmol})$ was added to a solution of $2 \mathrm{a}(61 \mathrm{mg}, 0.20 \mathrm{mmol})$ in THF $(5 \mathrm{~mL})$ at $-78{ }^{\circ} \mathrm{C}$. After stirring at $-78{ }^{\circ} \mathrm{C}$ for $1 \mathrm{~h}$, methyl iodide $(0.047 \mathrm{~mL}, 0.75 \mathrm{mmol})$ was added to the mixture and the whole was allowed to warm to room temperature over $1 \mathrm{~h}$. The reaction mixture was quenched with saturated aqueous $\mathrm{NH}_{4} \mathrm{Cl}(10 \mathrm{~mL})$, and the whole mixture was extracted with EtOAc $(2 \times 10 \mathrm{~mL})$. The combined organic layers were washed with water $(10 \mathrm{~mL})$ and brine $(10 \mathrm{~mL})$, and dried over anhydrous $\mathrm{MgSO}_{4}$. Filtration and evaporation in vacuo furnished the crude product, which was purified by column chromatography (silica gel, $4 \% \mathrm{Et}_{3} \mathrm{~N}$ in EtOAc) to provide 7 -methylated product $7 \mathrm{a}(133 \mathrm{mg}, 84 \%)$.

Typical procedure for the conversion of pyrrole derivatives 18,25 , and 29 to 4-substituted indole derivatives 10, 27, and 30 via conjugated olefins (Schemes 7, 9, and 10)

A solution of methyllithium ( $2.0 \mathrm{M}$ in $\left.\mathrm{Et}_{2} \mathrm{O}, 0.20 \mathrm{~mL}, 0.40 \mathrm{mmol}\right)$ was added to a solution of pyrrole $18(30 \mathrm{mg}, 0.10 \mathrm{mmol})$ in THF $(5 \mathrm{~mL})$ at $-78^{\circ} \mathrm{C}$. The mixture was allowed to warm to room temperature over $1 \mathrm{~h}$. The reaction mixture was quenched with $\mathrm{EtOH}(10 \mathrm{~mL})$, and the whole mixture was evaporated in vacuo. The residue was diluted with $\mathrm{CH}_{2} \mathrm{Cl}_{2}$ $(20 \mathrm{~mL})$, and the whole mixture was washed with water $(5 \mathrm{~mL})$ and brine $(5 \mathrm{~mL})$, and dried over anhydrous $\mathrm{MgSO}_{4}$. Filtration and evaporation in vacuo furnished the crude product $20(27 \mathrm{mg})$, which was used in the next step without further purfication.

Chloranil (37 mg, $0.15 \mathrm{mmol}$ ) was added to a solution of the crude product 20 in 1,4-dioxane $(1 \mathrm{~mL})$. The mixture was stirred at reflux for $1 \mathrm{~h}$ After cooling, the mixture was evaporated in vacuo. The residue was diluted with $\mathrm{Et}_{2} \mathrm{O}(10 \mathrm{~mL})$, and the whole mixture was washed with saturated aqueous $\mathrm{NaHCO}_{3}(3 \times 5 \mathrm{~mL})$, water $(5 \mathrm{~mL})$ and brine $(5 \mathrm{~mL})$, and dried over anhydrous $\mathrm{MgSO}_{4}$. Filtration and evaporation in vacuo furnished the crude product, which was purified by column chromatography (silica gel, $5 \%$ EtOAc in hexane) to provide 10a (19 mg, $64 \%)$.

\section{Acknowledgements}

This research was supported, in part, by a Grant-in-Aid for Scientific Research (C) (Grant No. JP15K07853) from the Japan Society for the Promotion of Science (JSPS).

Keywords: indole • regioselective alkylation • enaminone • dehydrogenation $\cdot$ spirocyclopropane

[1] a) E. Fattorusso, O. Taglialatela-Scafati, Modern Alkaloids: Structure, Isolation, Synthesis and Biology; Wiley-VCH: Weinheim, 2008; b) P. M. Dewick, Medicinal Natural Products: A Biosynthetic Approach; John Wiley \& Sons Inc.: Chichester, 2009; c) A. J. Kochanowska-Karamyan, M. T. Hamann, Chem. Rev. 2010, 110, 4489-4497; d) S.-M. Li, Nat Prod. Rep. 2010, 27, 57-78; e) M. Ishikura, T. Abe, T. Choshi, S Hibino, Nat. Prod. Rep. 2013, 30, 694-752; f) I. S. Marcos, R. F. Moro, I. Costales, P. Basabe, D. Díez, Nat. Prod. Rep. 2013, 30, 1509-1526; g) N. Netz, T. Opatz, Mar. Drugs 2015, 13, 4814-4914; h) T. V. Sravanthi, S. L. Manju, Eur. J. Pharm. Sci. 2016, 91, 1-10.

[2] For recent reviews, see: a) J. J. Song, J. T. Reeves, D. R. Fandrick, Z. Tan, N. K. Yee, C. H. Senanayake, ARKIVOC, 2010, i, 390-449; b) S Cacchi, G. Fabrizi, A. Goggiamani, Org. Biomol. Chem. 2011, 9 , 641-652; c) S. Cacchi, G. Fabrizi, Chem. Rev. 2011, 111, PR215-PR283; d) D. F. Taber, P. K. Tirunahari, Tetrahedron 2011, 67, 7195-7210; e) R. Vicente, Org. Biomol. Chem. 2011, 9, 6469-6480; f) M. Inman, C. J. Moody, Chem. Sci. 2013, 4, 29-41; g) N. Yoshikai, Y. Wei, Asian J. Org. Chem. 2013, 2, 466-478; h) T. Guo, F. Huang, L. Yu, Z. Yu, Tetrahedron Lett. 2015, 56, 296-302.

[3] For recent examples, see: a) N. Thies, C. G. Hrib, E. Haak, Chem. Eur. J. 2012, 18, 6302-6308; b) Lam, T. Y.; Wang, Y.-P.; Danheiser, R. L. J. Org. Chem. 2013, 78, 9396-9414; c) T. P. Willumstad, O. Haze, X. Y Mak, T. Y. Lam, Y.-P. Wang, R. L. Danheiser, J. Org. Chem. 2013, 78, 11450-11469; d) X. Feng, H. Wang, B. Yang, R. Fan, Org. Lett. 2014 16, 3600-3603; e) X. Li, H. Xie, X. Fu, J. Liu, H. Wang, B. Xi, P. Liu, X. Xu, W. Tang, Chem. Eur. J. 2016, 22, 10410-10414.

[4] a) R. C. Larock, E. K. Yum, J. Am. Chem. Soc. 1991, 113, 6689-6690; b) S. A. Worlikar, B. Neuenswander, G. H. Lushington, R. C. Larock, J. Comb. Chem. 2009, 11, 875-879. For reviews, see: c) G. Zeni, R. C. Larock, Chem. Rev. 2004, 104, 2285-2309; d) G. Zeni, R. C. Larock, Chem. Rev. 2006, 106, 4644-4680.

[5] For a review, see: K. Sapeta, T. P. Lebold, M. A. Kerr, Synlett 2011, 1495-1514.

[6] a) S. C. Banfield, D. B. England, M. A. Kerr, Org. Lett. 2001, 3, 3325-3327; b) P. V. Zawada, S. C. Banfield, M. A. Kerr, Synlett 2003, 971-974; c) D. B. England, M. A. Kerr, J. Org. Chem. 2005, 70, 6519-6522.

[7] a) S. K. Jackson, S. C. Banfield, M. A. Kerr, Org. Lett. 2005, 7, 1215-1218; b) D. B. England, J. Magolan, M. A. Kerr, Org. Lett. 2006, 8, 2209-2212; c) T. P. Lebold, M. A. Kerr, Org. Lett. 2007, 9, 1883-1886; d) M. D. Ganton, M. A. Kerr, J. Org. Chem. 2007, 72, 574-582; e) S. K. Jackson, M. A. Kerr, J. Org. Chem. 2007, 72, 1405-1411; f) A. B. Leduc, M. A. Kerr, Eur. J. Org. Chem. 2007, 237-240; g) T. P. Lebold, M. A. Kerr, Org. Lett. 2008, 10, 997-1000.

[8] a) H. Muratake, M. Natsume, Heterocycles 1989, 29, 771-782; b) H. Muratake, M. Natsume, Heterocycles 1989, 29, 783-794; c) M. Fuji, H. Muratake, M. Natsume, Chem. Pharm. Bull. 1992, 40, 2338-2343; d) M. 
Fuji, H. Muratake, M. Natsume, Chem. Pharm. Bull. 1992, 40 , 2344-2352.

[9] a) M. Fuji, H. Muratake, M. Akiyama, M. Natsume, Chem. Pharm. Bull. 1992, 40, 2353-2357; b) M. Sakagami, H. Muratake, M. Natsume, Chem. Pharm. Bull. 1994, 42, 1393-1398; c) H. Muratake, I. Abe, M. Natsume, Chem. Pharm. Bull. 1996, 44, 67-79; d) H. Muratake, N Matsumura, M. Natsume, Chem. Pharm. Bull. 1998, 46, 559-571.

[10] a) K. Yoshida, K. Hayashi, A. Yanagisawa, Org. Lett. 2011, 13 , 4762-4765; b) K. Hayashi, K. Yoshida, A. Yanagisawa, J. Org. Chem. 2013, 78, 3464-3469.

[11] For a review, see: A. H. Sandtorv, Adv. Synth. Catal. 2015, 357, 2403-2435.

[12] a) Q. Liu, Q. Li, Y. Ma, Y. Jia, Org. Lett. 2013, 15, 4528-4531; b) V. Lanke, K. R. Prabhu, Org. Lett. 2013, 15, 6262-6265; c) V. Lanke, K. R. Bettadapur, K. R. Prabhu, Org. Lett. 2016, 18, 5496-5499.

[13] Very recently, Shi and co-workers reported Pd- or Cu-catalyzed direct $\mathrm{C}-\mathrm{H}$ arylation of indoles at the $\mathrm{C} 4$ and $\mathrm{C} 5$ positions, respectively. $\mathrm{Y}$. Yang, P. Gao, Y. Zhao, Z. Shi, Angew. Chem. 2017, 129, 4024-4029; Angew. Chem. Int. Ed. 2017, 56, 3966-3971.

[14] a) S. Paul, G. A. Chotana, D. Holmes, R. C. Reichle, R. E. Maleczka, Jr., M. R. Smith, III, J. Am. Chem. Soc. 2006, 128, 15552-15553; b) D. W. Robbins, T. A. Boebel, J. F. Hartwig, J. Am. Chem. Soc. 2010, 132, 4068-4069; c) L. Xu, C. Zhang, Y. He, L. Tan, D. Ma, Angew. Chem. 2016, 128, 329-333; Angew. Chem. Int. Ed. 2016, 55, 321-325; d) $Y$. Yang, X. Qiu, Y. Zhao, Y. Mu, Z. Shi, J. Am. Chem. Soc. 2016, 138, 495-498; e) Y. Kim, J. Park, S. Chang, Org. Lett. 2016, 18, 1892-1895 e) Z. Song, A. P. Antonchick, Org. Biomol. Chem. 2016, 14 4804-4808; f) L. Xu, L. Tan, D. Ma, J. Org. Chem. 2016, 81 10476-10483
[15] Recently, Shi and co-workers reported Cu-catalyzed direct C6-arylation of indoles. Y. Yang, R. Li, Y. Zhao, D. Zhao, Z. Shi, J. Am. Chem. Soc. 2016, 138, 8734-8737.

[16] For recent reviews, see: a) M. A. Cavitt, L. H. Phun, S. France, Chem Soc. Rev. 2014, 43, 804-818; b) T. F. Schneider, J. Kaschel, D. B. Werz, Angew. Chem. 2014, 126, 5608-5628; Angew. Chem. Int. Ed. 2014, 53, 5504-5523; c) F. de Nanteuil, F. De Simone, R. Frei, F. Benfatti, E. Serrano, J. Waser, Chem. Commun. 2014, 50, 10912-10928; d) H. K. Grover, M. R. Emmett, M. A. Kerr, Org. Biomol. Chem. 2015, 13, 655-671; e) E. M. Budynina, K. L. Ivanov, I D. Sorokin, M. Y. Melnikov, Synthesis 2017, 49, 3035-3068.

[17] H. Nambu, M. Fukumoto, W. Hirota, T. Yakura, Org. Lett. 2014, 16 4012-4015.

[18] H. Nambu, M. Fukumoto, W. Hirota, N. Ono, T. Yakura, Tetrahedron Lett. 2015, 56, 4312-4315.

[19] Y. L. Chen, P. S. Mariano, G. M. Little, D. O’Brien, P. L. Huesmann, J. Org. Chem. 1981, 46, 4643-4654.

[20] A. A. Haddach, A. Kelleman, M. V. Deaton-Rewolinski, Tetrahedron Lett. 2002, 43, 399-402.

[21] a) E. Vedejs, D. A. Barda, Org. Lett. 2000, 2, 1033-1035; b) M Montesions-Magraner, C. Vila, A. Rendón-Patiño, G. Blay, I. Fernández, M. C. Muñoz, J. R. Pedro, ACS Catal.. 2016, 6, 2689-2693; c) M. Montesions-Magraner, C. Vila, G. Blay, I. Fernández, M. C. Muñoz, J. R. Pedro, Org. Lett. 2017, 19, 1546-1549.

[22] Alternatively, 22 was obtained by desilylation of $\mathbf{4 a}$.

[23] H. Nambu, N. Ono, W. Hirota, M. Fukumoto, T. Yakura, Chem. Pharm Bull. 2016, 64, 1763-1768. 
Entry for the Table of Contents (Please choose one layout)

\section{FULL PAPER}

The synthesis of highly substituted indoles via tetrahydroindol-4(5H)-one intermediates was developed. The synthesis of 5- and 7-substituted indoles was achieved by regioselective alkylation followed by oxidation to indoles. 4-Substituted indoles were synthesized by oxidation to the pyrrole derivative, alkylation with alkyllithium, and oxidation to the indole. Furthermore, the synthesis of 4,5,6,7-tetrasubstituted indoles was achieved by using these regioselective alkylations.

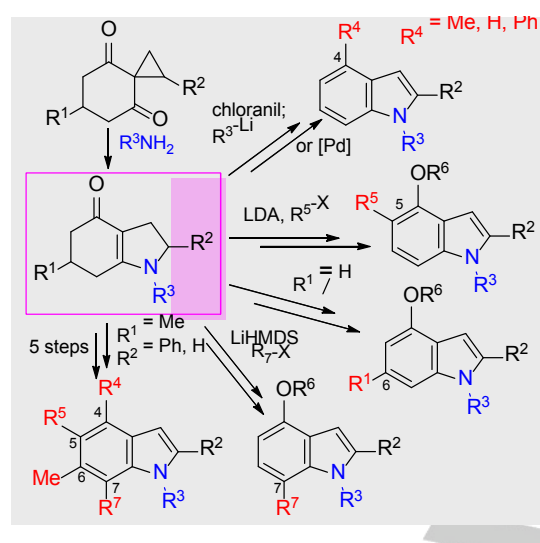

H. Nambu, * W. Hirota, M. Fukumoto, $T$. Tamura, T. Yakura*

Page No. - Page No.

An Efficient Route to Highly

Substituted Indoles via

Tetrahydroindol-4(5H)-one

Intermediates Produced by Ring-

Opening Cyclization of

Spirocyclopropanes with Amines 